\section{Questión}

Periodismo / Comunicación ISSN 1669-6581
- Av. $44 \mathrm{~N}^{\circ} 676,1^{\circ}$ piso

CP 1900 - La Plata - Argentina

www.perio.unlp.edu.ar/question

Serie web educativa: Coronavirus. Reflexiones para niñas, niños y jóvenes ciudadanos

Enrique Martínez

https://doi.org/10.24215/16696581e380

\title{
Serie web educativa: 'Coronavirus. Reflexiones para niñas, niños y jóvenes ciudadanos'
}

\section{Educational web series: 'Coronavirus. Reflections for girls, boys and young citizens'}

\begin{abstract}
Enrique A. Martínez
e.martinez@unia.es Jefe del Servicio Audiovisual de la Universidad Internacional de Andalucía, España, desde 1994. Codirector del Taller Telekids de educación mediática para niños. Lic. en Historia. Director de UNIA.tv, productor y director de documentales en Iberoamérica. Profesor de la Maestría de Comunicación Audiovisual de la UNIA y del Diplomado Internacional de Contenidos Audiovisuales para Público Infantil de la Univ. Santiago de Cali (Colombia). Profesor y coordinador del Curso de Experto en Producción de Contenidos Audiovisuales para Público Infantil de la UNIA. España
\end{abstract}

\section{Palabras Clave}

Infancias - Coronavirus - SerieWeb

\section{Key Words}

Childhood - Coronavirus - SerieWeb

La Universidad Internacional de Andalucía, a través de su Cátedra UNESCO de Derechos Humanos, pone en marcha la serie web educativa "Coronavirus. Reflexiones para niñas, niños y jóvenes ciudadanos". Una producción que tiene como objetivo enseñar los valores y conocimientos acerca de los derechos y libertades, en un contexto donde la pandemia del COVID-19 ha abierto diversos debates a nivel social y político.

Ruth Rubio, catedrática de Derecho Constitucional de la Universidad de Sevilla y directora de la Cátedra UNESCO de la UNIA, es la directora y conductora de esta serie publicada en la 
plataforma YouTube. A través de un lenguaje sencillo y directo, esta experta ofrece a los jóvenes detalles para que puedan entender aspectos como qué es el Estado de Derecho, cuáles son los mecanismos democráticos o qué desigualdades profundizan la pandemia.

La serie grabada en el confinamiento con su teléfono móvil por la profesora Rubio, ha tenido el asesoramiento y la postproducción del Servicio Audiovisual de la UNIA y la coordinación general del Área de Comunicación y la asesoría didáctica de una docente. En total la serie se compone de seis episodios que se irán difundiendo de manera semanal. El primero, 'Nuestro derecho a la información', acompañado de una guía didáctica, es una presentación de la serie, cuyo mensaje central es el derecho de los menores la información. En él se incide en su rol como miembros de la ciudadanía, siendo titulares de derechos fundamentales y por tanto, tienen el derecho y el deber de estar informados. Niñas, niños y jóvenes son personas que deben implicarse políticamente en el debate de la sociedad en la que habitan.

Ante ello, tienen derecho a exigir que la información les llegue de forma asequible y veraz, lo que implica contrastar la fuente, para, entre otros, evitar la propagación de bulos que dañan la convivencia y bases de la democracia. El segundo mensaje que se manda desde este episodio es sobre la importancia de la investigación y la transferencia del conocimiento en la formación de la opinión pública.

La guía didáctica de este primer capítulo consta de varios puntos: justificación, palabras clave, competencias clave, valores pedagógicos, actividades, recursos adicionales y un cuaderno de actividades. Por ejemplo, las palabras clave de este episodio son niños, ciudadanos, Constitución, derechos y libertades, información, opinión pública, fuente de la noticia y transferencia del conocimiento. Y las competencias clave son competencias sociales y cívicas, sentido de iniciativa y espíritu emprendedor, aprender a aprender, conciencia y expresiones culturales, competencia digital, comunicación lingüística y sentido crítico.

El derecho a la información es un derecho recogido en la Constitución española de 1978. El artículo 20 de la carta magna indica que se reconocen y protegen los derechos a recibir libremente información veraz por cualquier medio de difusión y que el ejercicio de este derecho no puede restringirse mediante ningún tipo de censura previa.

El segundo capítulo de la serie trata uno de los aspectos con los que la sociedad española ha tenido que familiarizarse desde el mes de marzo: el estado de alarma. Una situación inusual que ha limitado y modificado el día a día de millones de personas. 
En este vídeo se comentan las razones por las que un gobierno puede, de forma excepcional, obligar a los ciudadanos a estar confinados limitando así nuestra libertad de circulación. Para ello se explica de forma sencilla el concepto de estado de alarma, como estado de excepción que matizan las reglas básicas del funcionamiento del Estado de Derecho (separación de poderes y respeto a los derechos fundamentales).

La guía didáctica del segundo episodio es un documento accesible, de lenguaje fácil y muy útil para los más pequeños o para aquellos que no estén familiarizados con la organización del Estado español. En él se proponen varias actividades y se contextualiza el estado de alarma, provocado por una situación anormal. Un panorama que merece una explicación pormenorizada, empezando por niños y jóvenes, que es probable que estén desconcertados en el confinamiento. La guía contiene, además de vocabulario técnico relacionado con el estado de alarma, varios enlaces a webs donde profundizar en este asunto. Una de ellas es la del Congreso, donde están alojados los artículos de la Constitución. De él parten y a él llegan muchas de las reflexiones que se enuncian en esta serie. A esos recursos adicionales se unen varias preguntas para que el espectador concluya libremente con el visionado. Algunas de esas cuestiones son: ¿puede el gobierno actuar libremente en un estado de alarma? ¿por qué? Como jóvenes ciudadanos que sois... ¿qué debéis exigir al Gobierno? ¿has cambiado tu opinión sobre algo?

Unas interrogaciones que permiten abrir un debate en el seno familiar y observar los múltiples puntos de vista que pueden existir entre los jóvenes y mayores sobre la situación que vive España en particular y el mundo en general. La guía, acompañada del visionado del vídeo, surte de argumentos para la reflexión a quienes la lean.

Listado de episodios: "Coronavirus. Reflexiones para niñas, niños y jóvenes ciudadanos" Episodio 1: Nuestro derecho a la información. https://www.youtube.com/watch?v=ZDeuCXnUgjE Episodio 2: El estado de alarma. https://www.youtube.com/watch?v=luRHutEhm2s

Episodio 3: Confinamiento y derecho a la vivienda. https://www.youtube.com/watch? $v=66$ apzX2cCM

Episodio 4: Pandemia y solidaridad. https://www.youtube.com/watch?v=w920CwX3b3U

Episodio 5: El debate en Europa (1 de junio)

Episodio 6: La pandemia y género (8 de junio) 